\title{
Mouse Testicular Cell Type-Specific Antiviral Response against Mumps Virus Replication
}

\author{
Han Wu ${ }^{1,2 \dagger}$, Xiang Zhao't, Fei Wang ${ }^{1}$, Qian Jiang ${ }^{1}$, Lili Shi', Maolei Gong ${ }^{1}$, Weihua Liu', \\ Bo Gao ${ }^{2}$, Chengyi Song ${ }^{2}$, Qihan Li ${ }^{3}$, Yongmei Chen ${ }^{1}$ and Daishu Han ${ }^{1 *}$
}

'School of Basic Medicine, Peking Union Medical College, Institute of Basic Medical Sciences, Chinese Academy of Medical Sciences, Beijing, China, ${ }^{2}$ Joint International Research Laboratory of Agriculture and Agri-Product Safety, College of Animal Science and Technology, Institute of Epigenetics and Epigenomics, Yangzhou University, Yangzhou, China, ${ }^{3}$ Institute of Medical Biology, Chinese Academy of Medical Sciences, Kunming, China

\section{OPEN ACCESS}

Edited by:

Michael Harrison Hsieh, Children's National Medical Center,

Reviewed by:

Michael S. Diamond, Washington University School of Medicine, USA

Beatrix Schumak,

University of Bonn, Germany

*Correspondence:

Daishu Han

dshan@ibms.pumc.edu.cn

tThese authors have contributed equally to this work.

Specialty section:

This article was submitted to Microbial Immunology, a section of the journal

Frontiers in Immunology

Received: 31 October 2016 Accepted: 25 January 2017 Published: 10 February 2017

Citation:

Wu H, Zhao X, Wang F, Jiang $Q$,

Shi L, Gong M, Liu W, Gao B, Song $C, L i Q$, Chen $Y$ and Han $D$

(2017) Mouse Testicular Cell Type-Specific Antiviral Response against Mumps Virus Replication.

Front. Immunol. 8:117. doi: 10.3389/fimmu.2017.00117
Mumps virus (MuV) infection has high tropism to the testis and usually leads to orchitis, an etiological factor in male infertility. However, MuV replication in testicular cells and the cellular antiviral responses against MuV are not fully understood. The present study showed that MuV infected the majority of testicular cells, including Leydig cells (LC), testicular macrophages, Sertoli cells (SC), and male germ cells (GC). MuV was replicated at relatively high efficiencies in SC compared with LC and testicular macrophages. In contrast, MuV did not replicate in male GC. Notably, testicular cells exhibited different innate antiviral responses against MuV replication. We showed that interferon $\beta$ (IFN- $\beta$ ) inhibited MuV replication in LC, macrophages, and SC, which were associated with the upregulation of major antiviral proteins. We provided primary evidence that autophagy plays a role in blocking MuV replication in male GC. Autophagy was also involved in limiting MuV replication in testicular macrophages but not in Leydig and SC. These findings indicate the involvement of the innate defense against MuV replication in testicular cells.

Keywords: mumps virus, testicular cell, viral replication, innate antiviral response, autophagy

\section{INTRODUCTION}

Mumps virus (MuV) infection usually causes orchitis and may result in male infertility (1). Mumps orchitis is associated with direct $\mathrm{MuV}$ infection in the testis. Understanding the innate antiviral response against $\mathrm{MuV}$ replication in testicular cells can aid in the development of therapeutic strategies for mumps orchitis.

Mumps virus is an enveloped negative-sense RNA virus (2). An evident manifestation of MuV infection is painful parotitis, a contagious disease that occurs worldwide. MuV infection may also result in the inflammation of several other organs, including encephalitis, meningitis, myocarditis, pancreatitis, nephritis, and orchitis (3). Notably, mumps orchitis is the most common extra-salivary gland inflammation caused by $\mathrm{MuV}$ infection (4). The recovery of $\mathrm{MuV}$ from the testis and the semen of mumps orchitis patients suggest that a direct $\mathrm{MuV}$ infection in the testis is associated with diseases $(5,6)$. However, $\mathrm{MuV}$ infection and replication in testicular cells remain elusive.

Although humans are believed to be the only natural hosts, $\mathrm{MuV}$ also infects animal cells via its receptor, sialic acid, which is present on the surface of most animal cells (7). Viral replication in infected cells is controlled by cellular innate antiviral response. Type 1 interferon (IFN- $\alpha$ and IFN- $\beta$ ) production is a universal mechanism of the host's defense against viral infection (8). IFN- $\alpha$ 
and IFN- $\beta$ can be produced by most cell types in response to viral infection through the activation of pattern recognition receptors (PRRs) (9). Type 1 IFNs induce the expression of various antiviral proteins such as IFN-stimulated gene 15 (ISG15), $2^{\prime}$-5'-oligoadenylate synthetase 1 (OAS1), and Mx GTPase 1 (MX1), thereby inhibiting viral replication and degrading viral nucleic acids in infected cells (10). Type 1 IFNs also promote the host's adaptive immune response against viral infection (11). Recently, we showed that $\mathrm{MuV}$ infection induced IFN- $\alpha$ and IFN- $\beta$ production in Sertoli and Leydig cells (LC) (12). However, the role of IFNs in the testicular cell defense against $\mathrm{MuV}$ has yet to be clarified.

Autophagy is a conserved lysosome-dependent degradation pathway that breaks down dysfunctional organelles and large protein aggregates, which are involved in multiple pathophysiological conditions (13). Autophagy is also an intracellular innate defense mechanism against microbial infection by directly degrading microbes such as viruses, bacteria, and protozoa that invade cells $(14,15)$. The autophagy pathway is tightly regulated by a panel of autophagy-related proteins. Beclin-1 and microtubule-associated protein light chain 3 (LC3) are two critical autophagy-related proteins. Beclin-1 orchestrates different stages of autophagosome assembly (16), and LC3 is a hallmark of autophagosomal maturation (17).

The mammalian testis is a remarkable immumoprivileged organ necessary for protecting immunogenic germ cells (GC) from detrimental immune responses (18). To overcome immunoprivileged environment, the testis adapts local innate defense system against microbial infections (19). Although PRR-initiated innate immune responses to pathogen-associated molecules in testicular cells have been revealed, the functions of the innate immune responses in the testicular cell defense against live natural microbes need to be formally demonstrated. Moreover, male GC are equipped with autophagic machinery (20). The potential role of autophagy in the testicular cell defense against microbial infections has yet to be investigated. The present study elucidated the cell type-specific roles of IFN response and autophagy in mouse testicular cell defense against $\mathrm{MuV}$ replication.

\section{MATERIALS AND METHODS}

\section{Mice}

C57BL/6 mice were purchased from the Laboratory Animal Center of Peking Union Medical College. The mice were maintained in a specific pathogen-free facility with $12 / 12 \mathrm{~h}$ light/dark cycle and were provided with food and water ad libitum. All mice were handled in compliance with the Guidelines [permit number: SCXK (Jing) 2007-0001] for the Care and Use of Laboratory Animals established by the Chinese Council on Animal Care (Beijing, China). The protocol was approved by Animal Care and Use Committee of Institute of Basic Medical Sciences in China.

\section{Antibodies and Major Reagents}

Mouse anti-MuV nucleoprotein (MuV-NP) (ab9876), rat antiF4/80 (ab6640), and anti-IFN- $\beta$ (ab24324) mAbs were purchased from Abcam (Cambridge, UK). Rabbit anti-MX1 (sc-50509),
anti-LHR (sc-25828), anti-Wilms tumor nuclear protein 1 (WT1) (sc-192) polyclonal Abs, goat anti-Beclin-1 (sc-10086) polyclonal Abs, and mouse anti-OAS1 (sc-365072) mAb were purchased from Santa Cruz Biotechnology (Santa Cruz, CA, USA). Rabbit anti-ISG15 (\#2743) polyclonal Abs and anti-LC3 (\#4599) mAb were purchased from Cell Signaling Technology (Beverly, MA, USA). Mouse anti- $\beta$-actin (A5316) mAbs were purchased from Sigma-Aldrich (St. Louis, MO, USA). 4', 6' -diamidino2-phenylindole (DAPI), horseradish-peroxidase (HRP)-, and fluorescein isothiocyanate (FITC)-conjugated secondary Abs were purchased from Zhongshan Biotechnology (Beijing, China). Mouse recombinant IFN- $\beta$ (no. 19032) was purchased from Sigma-Aldrich. 3-methyladenine (3-MA) (tlrl-3ma) was purchased from InvivoGen (San Diego, CA, USA).

\section{Cell Isolation}

Testicular cells were isolated from 4-week-old C57BL/6 mice based on previously described procedures (21). The testes of three mice were decapsulated and incubated with $0.5 \mathrm{mg} / \mathrm{mL}$ collagenase type 1 (Sigma-Aldrich) in F12/DMEM (Life Technologies, Grand Island, NY, USA) at room temperature for 15 min with gentle oscillation. The suspensions were filtered through $80-\mu \mathrm{m}$ copper mesh to separate interstitial cells from the seminiferous tubules. The interstitial cells were cultured in F12/DMEM supplemented with $100 \mathrm{U} / \mathrm{mL}$ penicillin, $100 \mathrm{mg} / \mathrm{mL}$ streptomycin, and $10 \%$ fetal calf serum (FCS; Life Technologies). After $24 \mathrm{~h}$, LC were detached by treatment with $0.125 \%$ trypsin for $5 \mathrm{~min}$. Testicular macrophages remained attached on culture dishes after the trypsin treatment. The purities of LC and macrophages were assessed by immunostaining for luteinizing hormone receptor (LHR), a marker of LC (22), and for F4/80, a marker of macrophages (23).

The seminiferous tubules were incubated with $0.5 \mathrm{mg} / \mathrm{mL}$ collagenase type 1 for $15 \mathrm{~min}$ at room temperature to remove peritubular myoid cells. The tubules were cut into small pieces of approximately $1 \mathrm{~mm}$ and incubated with $0.5 \mathrm{mg} / \mathrm{mL}$ hyaluronidase (Sigma-Aldrich) at room temperature for $10 \mathrm{~min}$ with gentle pipetting to dissociate GC from Sertoli cells (SC). Suspensions were cultured with F12/DMEM at $32^{\circ} \mathrm{C}$ for $6 \mathrm{~h}$. The GC were recovered by collecting non-adherent cells. The germ cell purity was assessed based on cell nuclear morphology after staining with DAPI (24). SC were cultured for additional $24 \mathrm{~h}$ and then treated with a hypotonic solution (20 mM Tris, $\mathrm{pH} 7.4$ ) for $1 \mathrm{~min}$ to remove adhering GC. The purity of SC was assessed by immunofluorescence staining of WT1, a marker of SC (25). Testicular cells were incubated in a humidified atmosphere containing 5\% $\mathrm{CO}_{2}$ at $32^{\circ} \mathrm{C}$.

\section{MuV Infection}

Mumps virus (SP-A strain) was isolated from mumps patients (26) and obtained from the Institute of Medical Biology, Chinese Academy of Medical Sciences (Kunming, China). MuV was amplified and titrated in Vero cells. MuV preparations were diluted in $1 \times \mathrm{PBS}$ at a density of $1 \times 10^{9}$ plaque forming unit $/ \mathrm{mL}$ and stored at $-80^{\circ} \mathrm{C}$. For infection, testicular cells were inoculated with $\mathrm{MuV}$ for $2 \mathrm{~h}$. Cells were treated with $0.25 \%$ trypsin for $5 \mathrm{~min}$ at room temperature to remove $\mathrm{MuV}$ attaching on cell 
surfaces. After washing thrice with PBS, cells were cultured in F12/DMEM supplemented with $100 \mathrm{U} / \mathrm{mL}$ penicillin, $100 \mathrm{mg} /$ $\mathrm{mL}$ streptomycin, and 10\% FCS.

\section{Plaque Assay}

Mumps virus titers were assessed using plaque assay in Vero cells. Briefly, Vero cells were cultured in 6-well plates at $2 \times 10^{5}$ cells/well and infected with a serial dilution of MuV for $1 \mathrm{~h}$. Cells were washed three times with PBS and then cultured in DMEM containing 2\% FCS and 1.5\% methylcellulose. After 1 week, cells were stained with $1 \%$ crystal violet solution (Sigma-Aldrich) in accordance with the manufacturer's instructions. Plaques were counted and represented $\mathrm{MuV}$ particles.

\section{MTT Assay}

Cell viability was assessed using an MTT Assay Kit (ATCC, Manassas, VA, USA) in accordance with the manufacturer's instructions. In brief, cells were cultured in 96-well microplates at a density of $2 \times 10^{4}$ cells/well. After treatments with $\mathrm{MuV}$ and 3-MA, cells were incubated with $10 \mu \mathrm{L}$ of MTT solution for $2 \mathrm{~h}$. Then, $100 \mu \mathrm{L}$ of detergent reagent, which was included in the kit, was added to each well. Absorbance at $570 \mathrm{~nm}$ was determined with a microplate reader (BioTek, Winooski, VT, USA). The percentage of the absorbance value versus the control value represents cell viability.

\section{Real-time Quantitative RT-PCR (qRT-PCR)}

Total RNA was extracted with Trizol ${ }^{\mathrm{TM}}$ reagent (Invitrogen, Carlsbad, CA, USA) in accordance with the manufacturer's instructions. RNA was treated with RNase-free DNase 1 (Invitrogen) to eliminate potential DNA contaminants. RNA $(1 \mu \mathrm{g})$ was reverse transcribed into cDNA in a $20 \mu \mathrm{L}$ reaction mixture containing $2.5 \mu \mathrm{M}$ random hexamers, $2 \mu \mathrm{M}$ dNTPs, and $200 \mathrm{U}$ Moloney murine leukemia virus reverse transcriptase (Promega, Madison, WI, USA). PCR was performed using a Power SYBR ${ }^{\circledR}$ Green PCR Master Mix Kit (Applied Biosystems, Foster City, CA, USA) on an ABI PRISM 7300 real-time cycler (Applied Biosystems). Relative mRNA levels were determined by the comparative $2^{-\Delta \Delta C T}$ method as described in the Applied Biosystems User Bulletin No. 2 (P/N 4303859) (27). The primer sequences are listed in Table 1.

\section{Western Blot Analysis}

The cells were lysed with a lysis buffer (Applygen Technologies Inc., Beijing, China), and the protein concentrations were determined with a Bicinchoninic Acid Protein Assay Kit (Pierce Biotechnology, Rockford, IL, USA). Proteins (20 $\mu \mathrm{g} /$ well) were separated on $12 \%$ SDS-PAGE gel and then electrotransferred onto polyvinyl difluoride membranes (Millipore, Bedford, MA, USA). The membranes were blocked with Tris-buffered saline (TBS, pH 7.4) containing 5\% non-fat milk at room temperature for $1 \mathrm{~h}$ and then incubated with the primary antibodies overnight at $4^{\circ} \mathrm{C}$. The membranes were washed twice with TBS containing $0.1 \%$ Tween-20 and then incubated with the HRP-conjugated secondary antibodies at room temperature for $1 \mathrm{~h}$. Ag/Ab complexes were visualized with an enhanced Chemiluminescence Detection Kit (Zhongshan Biotechnology Co.). $\beta$-Actin was used as the loading control.

\section{Immunohistochemistry and Immunofluorescence Staining}

The testes were fixed in Bouin's solution for $24 \mathrm{~h}$ and then embedded in paraffin. Sections ( $5 \mu \mathrm{m}$ in thickness) were cut using rotary microtome Reichert 820 HistoSTAT (Reichert Technologies, NY, USA). After dewaxing process, the sections were incubated with $3 \% \mathrm{H}_{2} \mathrm{O}_{2}$ in $\mathrm{PBS}$ for $15 \mathrm{~min}$ at room temperature to inhibit endogenous peroxidase activity. The slides were soaked in citrate buffer and microwave heated at $100^{\circ} \mathrm{C}$ for 10 min to retrieve the antigens. After blocking with 5\% normal goat sera in PBS for $1 \mathrm{~h}$ at room temperature, the sections were incubated with primary antibodies overnight at $4^{\circ} \mathrm{C}$. After washing twice with PBS, the sections were incubated with appropriate FITC- or HRP-conjugated secondary antibodies (Zhongshan Biotechnology Co.) at room temperature for $30 \mathrm{~min}$. HRP activity was visualized using the diaminobenzidine method. Negative controls were incubated with appropriate pre-immune animal (rabbit, rat, or mouse) sera instead of primary antibodies. The sections were counterstained with DAPI in immunofluorescence staining or with hematoxylin in immunohistochemical staining and then mounted with neutral balsam (Zhongshan Biotechnology Co.) for observation.

For indirect immunofluorescence staining, cells were fixed with $-20^{\circ} \mathrm{C}$ pre-cooled methanol for $3 \mathrm{~min}$ and then permeabilized with $0.2 \%$ Triton X-100 in PBS for 15 min. The cells were blocked with $5 \%$ normal goat sera for $30 \mathrm{~min}$ at room temperature and then incubated with primary antibodies at $37^{\circ} \mathrm{C}$ for $90 \mathrm{~min}$. The cells were washed twice with PBS and incubated with appropriate FITC-conjugated secondary antibodies (Zhongshan Biotechnology Co.) for $30 \mathrm{~min}$ at $37^{\circ} \mathrm{C}$. The slides were mounted with antifade mounting medium (Zhongshan Biotechnology Co.)

TABLE 1 | Primers used for real-time PCR.

Target genes
Primer pairs $\left(5^{\prime}-3^{\prime}\right)$

Forward
TCAGATCAATCGCATCGGGG
CCAGTCTCTGACTGTGAGAGC
ATTACCTCCTTCCCGACACC
GACCATAGGGGTCTTGACCAA
GAGCCATTATTGAAACTCGCCA
GCGAGTTGGTCAAGATCATCC
GAAATCGTGCGTGACATCAAAG

Reverse

CTTGCGACTGTGCGTITGA GCATCACTGTGCTGCTGGGAC CAAACTCCACCTCCTGATGC AGACTTGCTCTTTCTGAAAAGCC CCTCCCCGATCAGAGTGAA ATGTCAGCGATGGGTGTGGA TGTAGTTTCATGGATGCCACAG 
and observed under a fluorescence microscope BX-51 (Olympus, Tokyo, Japan).

\section{Statistical Analysis}

Data were presented as the mean \pm SEM of at least three independent experiments. Statistical difference between two groups was determined using Student's $t$-test. One-way ANOVA with Bonferroni's (selected pairs) post hoc test was used for multiple comparisons. The calculations were performed with SPSS version 13.0 (SPSS Inc., Chicago, IL, USA). $P<0.05$ was considered statistically significant.

\section{RESULTS}

\section{MuV Infection of Testicular Cells}

To examine $\mathrm{MuV}$ infection of testicular cells, including LC, testicular macrophages, SC, and GC were isolated from 4-weekold C57BL/6 male mice. Cell purity was assessed using indirect immunofluorescence staining of LHR for LC, F4/80 for macrophages, and WT1 for SC (Figure 1A). Germ cell purity was assessed based on nuclear morphology after staining with DAPI (Figure 1A, right panel). The purity of LC and macrophages was $>92 \%$, and the purity of Sertoli and GC was $>95 \%$. To determine
A

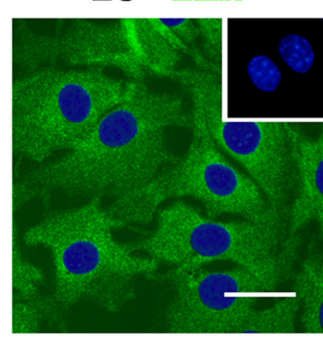

B

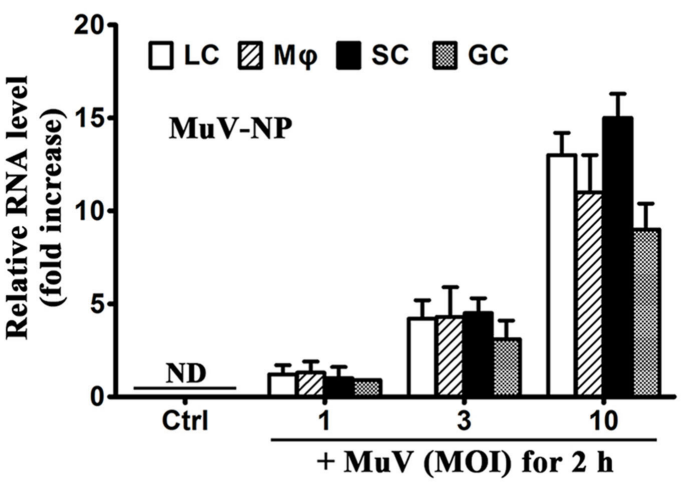

$\mathrm{M \varphi}+\mathrm{F} 4 / 80$

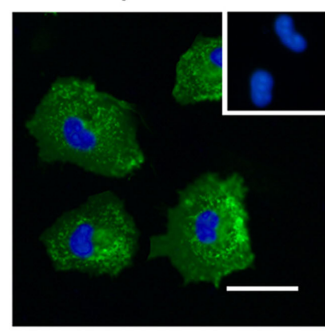

C
D

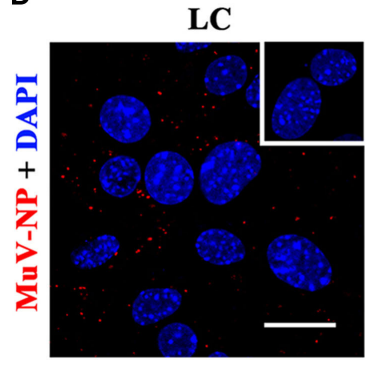

М甲

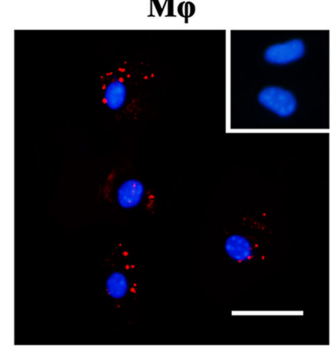

$\mathbf{S C}+$ WT1
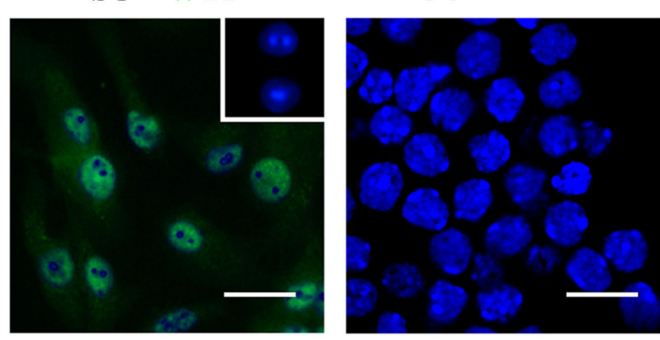

$\underset{(10 \mathrm{MOI})}{\operatorname{MuV}} \frac{\mathrm{LC}}{-+} \frac{\mathrm{M} \varphi}{-+} \frac{\mathrm{SC}}{-+} \frac{\mathrm{GC}}{-+\mathrm{kDa}}$

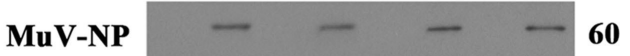

及-Actin

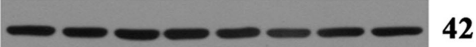

SC

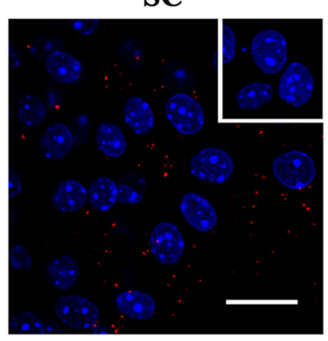

GC

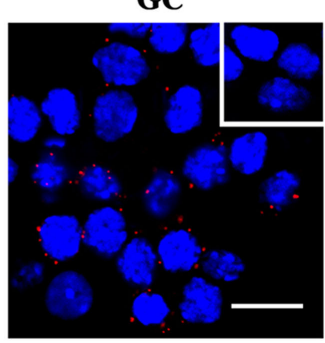

FIGURE 1 Identification and mumps virus (MuV) infection of testicular cells. Major testicular cells, including Leydig cells (LC), macrophages (M cells (SC), and germ cells (GC), were isolated from 4-week-old C57BL/6 male mice. (A) Identification of cell purity. Purities of somatic cells were determined using indirect immunofluorescence staining of cell markers, luteinizing hormone receptor (LHR) for LC, F4/80 for M 4 , and Wilms tumor nuclear protein 1 (WT1) for SC. Insets in the upper right corners represent negative controls (Ctrl), in which pre-immune rabbit or rat sera served as primary antibodies, respectively. GC purity was assessed by nuclear morphologies after staining with 4', 6'-diamidino-2-phenylindole (DAPI). (B) MuV nuclear protein (MuV-NP) RNA level in infected cells. Testicular cells were infected with the indicated multiplicity of infection (MOI) of MuV for $2 \mathrm{~h}$. Total RNAs were extracted, and relative RNA levels of MuV-NP were determined using quantitative real-time PCR (qRT-PCR). Cells without MuV infection served as Ctrl. ND, not detectable. (C) Protein levels of MuV-NP. Cells were uninfected or infected with $10 \mathrm{MOI}$ MuV for $2 \mathrm{~h}$, and MuV-NP was determined using Western blot analysis. $\beta$-Actin was used as the loading control. (D) MuV particles. Testicular cells were infected with $10 \mathrm{MOI} \mathrm{MuV}$ for $2 \mathrm{~h}$. Intracellular MuV was assessed using immunofluorescence staining of MuV-NP. Insets in the upper right corners represent negative Ctrl, in which pre-immune mouse sera served as primary antibodies. Images represent at least three independent experiments. Data are presented as the means \pm SEM of three experiments. Scale bars, $20 \mu \mathrm{m}$. 
$\mathrm{MuV}$ infection in testicular cells, the levels of genomic MuV-NP RNA were examined by real-time qRT-PCR at $2 \mathrm{~h}$ after infection with different doses of $\mathrm{MuV}$ (Figure 1B). MuV-NP RNA was undetectable in control cells without $\mathrm{MuV}$ infection. Western blot analysis results showed that the MuV-NP protein levels in the testicular cells at $2 \mathrm{~h}$ after infection with 10 multiplicity of infection (MOI) $\mathrm{MuV}$ (Figure 1C). MuV-NP proteins in testicular cells were confirmed by immunofluorescence staining at $2 \mathrm{~h}$ after infection with $10 \mathrm{MOI}$ MuV (Figure 1D). These findings suggest that $\mathrm{MuV}$ infects major testicular cells.

\section{MuV Replication in Testicular Cells}

To evaluate $\mathrm{MuV}$ replication, we examined $\mathrm{MuV}-\mathrm{NP}$ expression in testicular cells and viral titers in culture media. Real-time qRT-PCR analysis showed that MuV-NP RNA levels were increased in SC in a time-dependent manner after infection with one MOI MuV (Figure 2A). MuV-NP RNA levels were also evidently increased in LC and macrophages. Notably, the peak MuV-NP RNA level in SC was about 10-fold higher than that in $\mathrm{LC}$ and macrophages. In contrast, the level of MuV-NP RNA in male GC did not significantly increase. Western blot analysis also confirmed that the MuV-NP protein levels were apparently increased in testicular somatic cells but not in GC at $48 \mathrm{~h}$ post $\mathrm{MuV}$ infection (Figure 2B). Plaque forming assay results showed that $\mathrm{MuV}$ titers in the media of testicular somatic cells were increased in a time-dependent manner (Figure 2C). MuV titers were not increased in the media of male GC. These observations indicated that $\mathrm{MuV}$ significantly replicate in testicular somatic cells but not in male GC.

\section{Inhibition of MuV Replication by IFN- $\beta$}

Given that IFN- $\beta$ is a critical antiviral cytokine (28), we examined the effect of recombinant IFN- $\beta$ on $\mathrm{MuV}$ replication in testicular cells. The cells were infected with one MOI MuV in the presence of different doses of IFN- $\beta$. Real-time qRT-PCR analysis showed that the presence of $200 \mathrm{U} / \mathrm{mL}$ IFN- $\beta$ significantly reduced the MuV-NP RNA levels in LC, macrophages, and SC at $48 \mathrm{~h}$ after $\mathrm{MuV}$ infection (Figure 3A). In contrast, IFN- $\beta$ did not affect the MuV-NP RNA levels of male GC (Figure 3A, right panel). Western blot analysis confirmed that IFN- $\beta$ evidently decreased the MuV-NP protein levels in Leydig, macrophages, and SC (Figure 3B). MuV-NP protein levels in male GC were not altered by IFN- $\beta$. Plaque forming assay results showed that $\mathrm{MuV}$ titers in the media of testicular somatic cells were significantly reduced by IFN- $\beta$ at $48 \mathrm{~h}$ after $\mathrm{MuV}$ infection (Figure 3C). These results imply that exogenous IFN- $\beta$ significantly inhibits $\mathrm{MuV}$ replication in testicular somatic cells but not GC.

\section{Induction of Antiviral Proteins by IFN- $\beta$}

Considering that IFN-inducible antiviral proteins play crucial roles in restricting viral replication in infected cells (8), we examined the expression of major antiviral proteins, including ISG15, OAS1, and MX1, in testicular cells in response to IFN- $\beta$ treatment. Real-time qRT-PCR results (Figure 4A) showed that the presence of $200 \mathrm{U} / \mathrm{mL}$ IFN- $\beta$ dramatically increased the mRNA levels of ISG15 (left panel), OAS1 (middle panel), and MX1 (right panel) in LC, macrophages, and SC at $8 \mathrm{~h}$
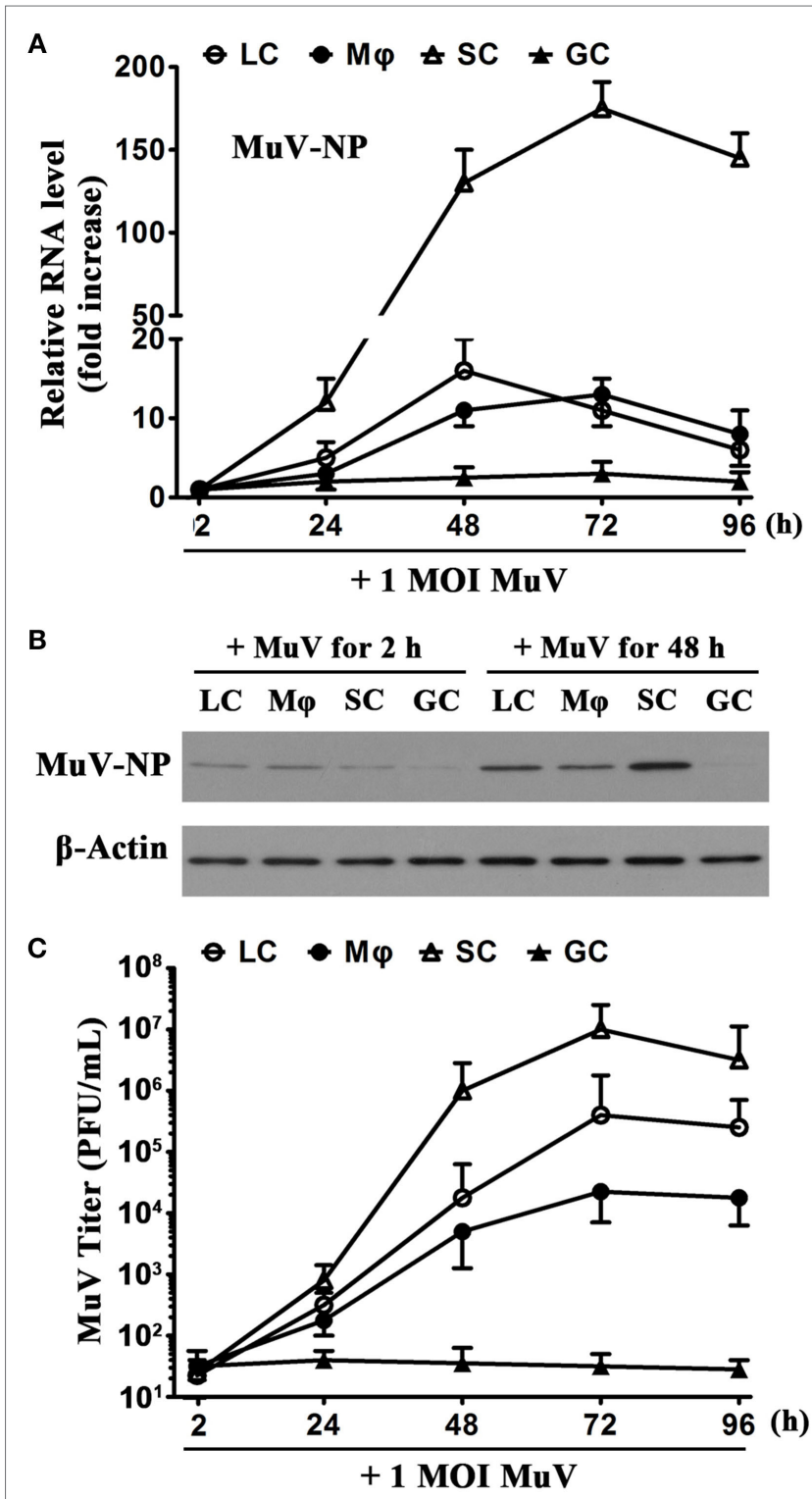

FIGURE 2 | Mumps virus (MuV) replication. (A) Time-dependent MuV replication in testicular cells. Cells were seeded in 6-well plates at a density of $2 \times 10^{5} /$ well and infected with one multiplicity of infection (MOI) MuV for specific durations. Relative RNA levels of MuV-NP were determined using real-time qRT-PCR. (B) Protein levels of MuV-NP. Cells were infected with 1 MOI MuV. MuV-NP protein levels in testicular cells at 2 and $48 \mathrm{~h}$ after infection were determined using Western blot analysis. (C) MuV titers. Cells were infected as described in (A). MuV titers in the culture media were analyzed using plaque assay. PFU, plaque forming unit. The limit of detection was 10. Images represent at least three independent experiments. Date are presented as the means \pm SEM of three experiments.

post-infection. IFN- $\beta$ insignificantly induced the antiviral protein mRNA levels of male GC. Western blot analysis confirmed that the antiviral protein levels were significantly upregulated in the testicular somatic cells $24 \mathrm{~h}$ after the presence of IFN- $\beta$ (Figures $4 \mathrm{~B}, \mathrm{C}$ ). In contrast, IFN- $\beta$ did not increase the levels of the antiviral proteins in male GC. 

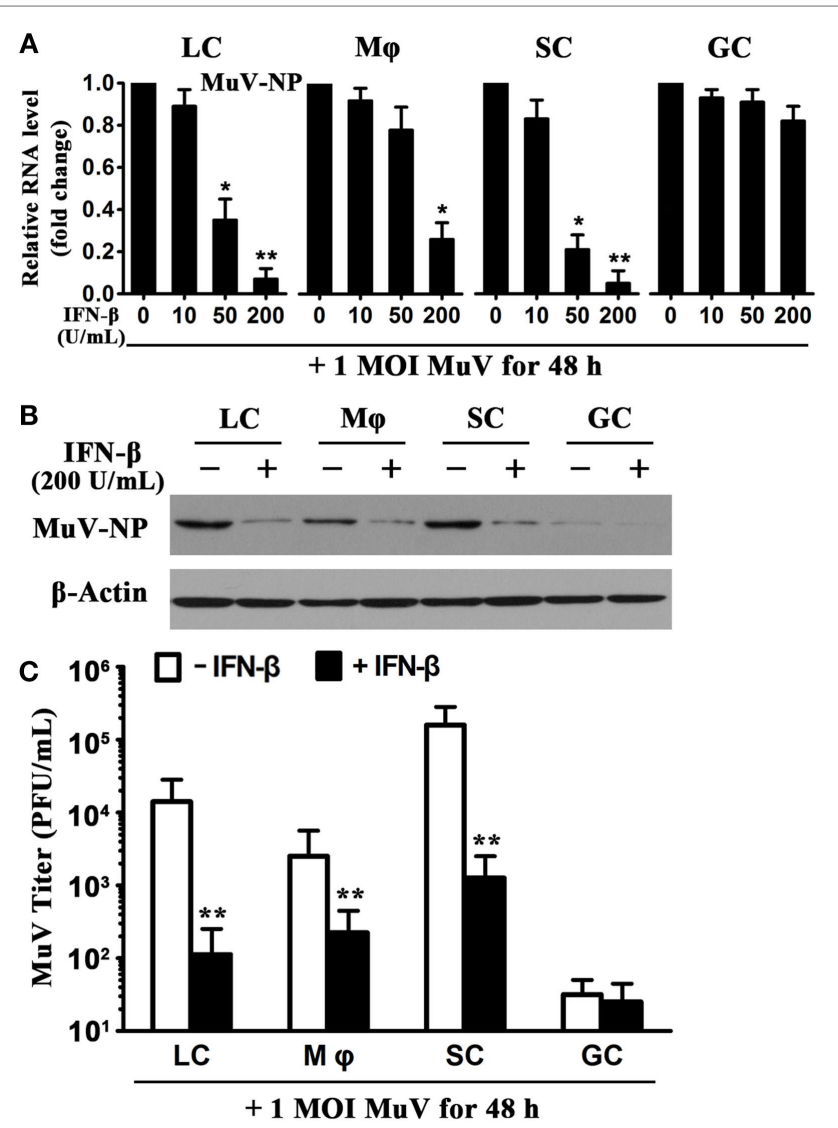

FIGURE 3 | Inhibition of mumps virus (MuV) replication by interferon $\boldsymbol{\beta}$ (IFN- $\boldsymbol{\beta}$ ). (A) A dose-dependent IFN- $\beta$ inhibition of MuV replication. Testicular cells were seeded in 6-well plates at a density of $2 \times 10^{5}$ cells/well and infected with one multiplicity of infection (MOI) MuV in the presence of the indicated doses of IFN- $\beta$. After $48 \mathrm{~h}$, total RNAs were extracted, and relative RNA levels of MuV-NP were determined using real-time qRT-PCR. (B) Protein levels of MuV-NP. Cells were infected with $1 \mathrm{MOI}$ MuV in the absence and presence of $200 \mathrm{U} / \mathrm{mL}$ IFN- $\beta$. At $48 \mathrm{~h}$ after MuV infection, MuV-NP was determined using Western blot analysis. (C) MuV titers. Cells were treated as described in (B). MuV titers in culture media were analyzed using plaque forming assay. The limit of detection was 10. Images represent at least three independent experiments. Data are presented as the means \pm SEM of three experiments $\left({ }^{*} p<0.05,{ }^{* *} p<0.01\right)$

\section{Role of MuV-Induced IFN- $\beta$ in Antiviral Response}

Given that MuV induces IFN- $\beta$ production in Sertoli and LC (12), we speculated that $\mathrm{MuV}$-induced IFN- $\beta$ is involved in antiviral responses in testicular somatic cells. Therefore, we examined the effects of neutralizing antibodies against IFN- $\beta$ on $\mathrm{MuV}$ replication. The presence of $5 \mu \mathrm{g} / \mathrm{mL}$ anti-IFN- $\beta$ antibodies evidently increased MuV-NP RNA (Figure 5A, upper panel) and protein (low panel) levels in LC and macrophages at $48 \mathrm{~h}$ after infection with $1 \mathrm{MOI} \mathrm{MuV}$. The increases in MuV-NP RNA and protein levels by anti-IFN- $\beta$ antibodies were less evident in SC. Accordingly, the anti-IFN- $\beta$ antibodies significantly increased $\mathrm{MuV}$ titers in the culture media (Figure 5B). The mRNA (upper panel) and protein (low panels) levels of ISG15 were remarkably increased in the testicular cells at $48 \mathrm{~h}$ after $\mathrm{MuV}$ infection (Figure 5C). The $\mathrm{MuV}$-induced ISG15 levels were significantly reduced in the presence of antiIFN- $\beta$ antibodies. Similarly, MuV significantly increased OAS1 (Figure 5D) and MX1 (Figure 5E) levels, which were reduced by the anti-IFN- $\beta$ antibodies.

\section{Autophagic Machinery in Testicular Cells}

To assess autophagy in testicular cells, we examined the expression of two major autophagy-related proteins, namely, beclin-1 and LC3. Real-time qRT-PCR results showed that male GC abundantly expressed beclin-1 and LC3 at mRNA levels (Figure 6A). The mRNA levels of beclin-1 and LC3 were relatively low in Leydig and SC. Beclin-1 and LC3 mRNAs were also evident in macrophages. Western blot analysis also detected the protein expression of beclin-1 and LC3 in testicular cells (Figure 6B). The most abundant type II LC3 (LC3-II) was detected in male GC, suggesting that these cells are capable of autophagy. Moreover, the beclin-1 and LC3 proteins were evidently detected in macrophages, suggesting that testicular macrophages are also well equipped with autophagic machinery. In contrast, the beclin-1 and LC3 were faintly detected in Leydig and SC. Immunohistochemistry analysis confirmed that beclin-1 (Figure 6C, upper panels) was localized in spermatogonia (black arrows), spermatocytes (black arrowheads), round spermatids (white arrows), and interstitial cells (black asterisks). In contrast, beclin-1 was not evident in SC (white arrowheads). LC3 was predominantly localized to round and elongating spermatids (white asterisks) (Figure 6C, lower panel). LC3 was also detected in interstitial cells.

\section{Role of Autophagy in Limiting MuV Replication}

The effect of 3-MA (an autophagy inhibitor) on $\mathrm{MuV}$ replication in testicular cells was examined to determine the role of autophagy in antiviral ability. The presence of 3-MA for $24 \mathrm{~h}$ inhibited the LC3-II level of GC and macrophages in a dose-dependent manner (Figure 7A, upper panels). 3-MA at concentrations of 5 and $20 \mu \mathrm{M}$ remarkably reduced LC3-II levels. In contrast, 3-MA did not affect the LC3 levels in Leydig and SC (Figure 7A, lower panels). Moreover, the application of $5 \mu \mathrm{M}$ of 3 -MA induced a reduction in LC3-II levels of male GC and macrophages in a time-dependent manner (Figure 7B). LC3-II levels were remarkably reduced at $24 \mathrm{~h}$ after the presence of 3-MA. Notably, 3-MA significantly increased MuV-NP RNA levels in male GC and macrophages at $48 \mathrm{~h}$ after the cells were infected with one MOI $\mathrm{MuV}$ (Figure 7C, upper panel). In contrast, 3-MA did not significantly affect the MuV-NP RNA levels in Leydig and SC. Results of Western blot analysis showed that 3-MA increased MuV-NP protein levels in male GC and macrophages, but not in Leydig and SC (Figure 7C, lower panel). Immunofluorescence staining confirmed that MuV-NP numbers were increased by 3-MA in macrophages (Figure 7D, left panels) and male GC (right panels). The presence of 3-MA did not affect MuV-NP numbers in Leydig and SC (data not shown). Accordingly, 3-MA significantly increased the $\mathrm{MuV}$ titers in the culture media of GC and macrophages but not in that of the Leydig and SC (Figure 7E). Furthermore, 

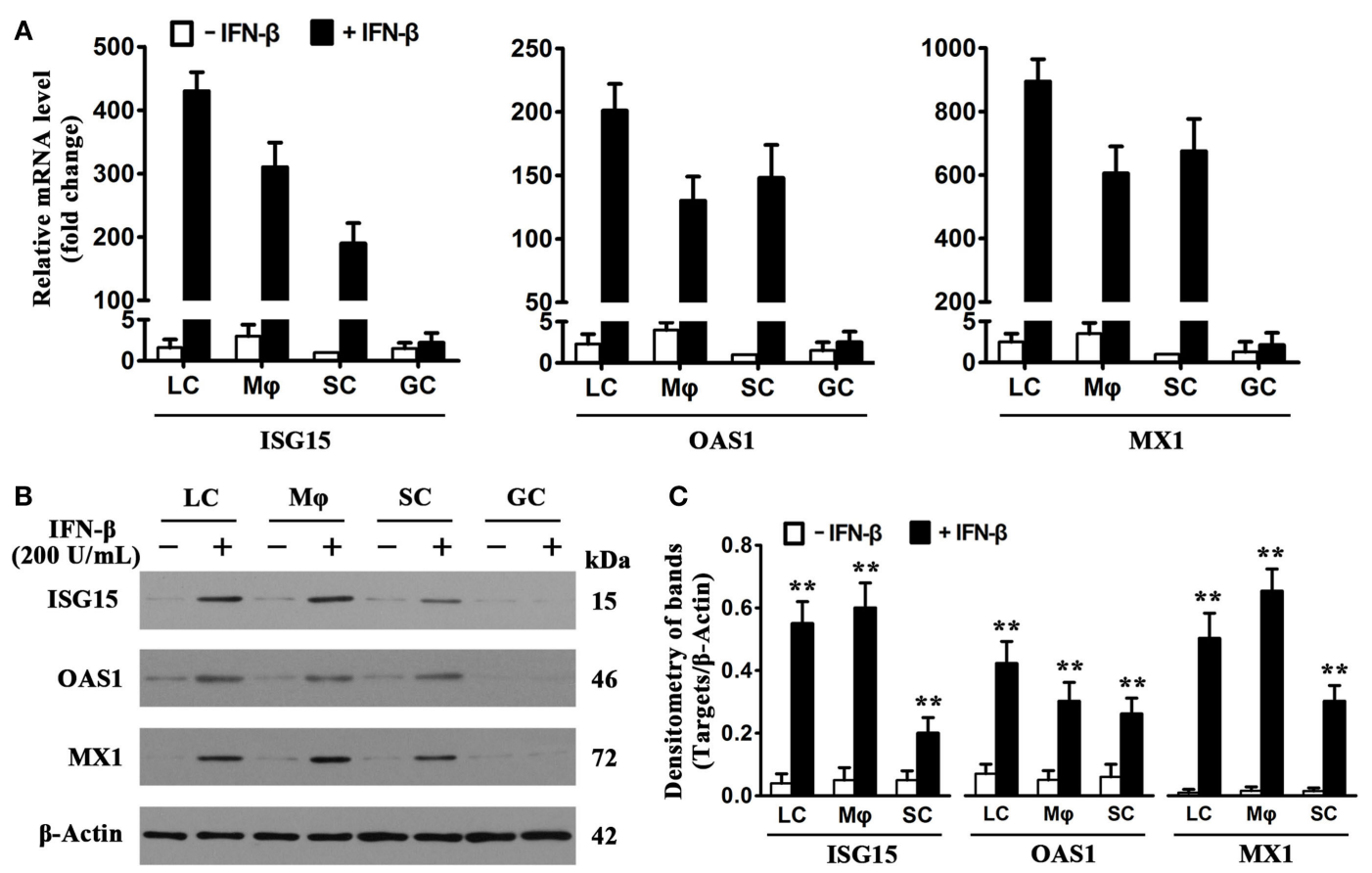

FIGURE 4 | Induction of antiviral proteins by interferon $\boldsymbol{\beta}$ (IFN- $\boldsymbol{\beta})$. (A) mRNA levels of antiviral proteins. Testicular cells were cultured in the absence and presence of $200 \mathrm{U} / \mathrm{mL}$ IFN- $\beta$ for 8 h. Total RNA was extracted, and relative mRNA levels of major antiviral proteins, including IFN-stimulated gene 15 (ISG15), 2'-5'-oligoadenylate synthetase 1 (OAS1), and Mx GTPase 1 (MX1), were determined using real-time qRT-PCR. The lowest mRNA levels of the antiviral proteins were set as "1." Fold changes normalizing to 1 were presented. Data are presented as the means \pm SEM of three independent experiments. (B) Protein levels of the antiviral proteins. Testicular cells were cultured in the absence and the presence of $200 \mathrm{U} / \mathrm{mL}$ IFN- $\beta$ for $24 \mathrm{~h}$, cell lysates were subjected to Western blot analysis. (C) Antiviral protein levels were quantitatively analyzed by measuring densitometry of bands in Western blots. Images represent at least three independent experiments. Data are presented as the means \pm SEM of three experiments $\left({ }^{\star} p<0.05,{ }^{* *} p<0.01\right)$.

3-MA treatment and $\mathrm{MuV}$ infection did not significantly affect the survival of testicular cells (Figure 7F).

\section{DISCUSSION}

The global resurgence of mumps orchitis warrants an in-depth understanding of $\mathrm{MuV}$ replication in the testis (29). Unraveling the mechanisms underlying the innate antiviral response against $\mathrm{MuV}$ in the testis can aid in the development of preventive and therapeutic strategies for mumps orchitis. The present study investigated $\mathrm{MuV}$ replication in testicular cells and cell typespecific antiviral mechanisms. We demonstrated that major testicular cells exhibited different innate antiviral mechanisms against $\mathrm{MuV}$ replication.

The present study focused on major testicular cells, including LC, testicular macrophages, Sertoli, and male GC. We used testicular cells from 4-week-old mice based on their ease in isolation from the testis of mice at this particular age. Orchitis occurs in about $40 \%$ of pubertal and postpubertal mumps in men and may result in male infertility at a high incidence rate (30). Although mumps orchitis incidence had dramatically declined following the administration of $\mathrm{MuV}$ vaccines in children, a recent outbreak of mumps orchitis in postpubertal men is threatening male fertility (31). Studies on MuV replication in testicular cells may facilitate in the elucidation of the mechanisms underlying the development of mumps orchitis. The present study has shown that $\mathrm{MuV}$ infects major testicular cells, although its replication in different types of testicular cells varies. The highest rate of $\mathrm{MuV}$ replication was observed in SC, followed by LC and macrophages. In contrast, $\mathrm{MuV}$ did not replicate in male GC. These observations suggest that testicular cells possess different mechanisms to control $\mathrm{MuV}$ replication. The mechanisms by which testicular cells control $\mathrm{MuV}$ replication is worthy investigating.

Type 1 IFNs are inducible during viral infection and considered as the primary antiviral response (28). IFN- $\alpha$ and IFN- $\beta$ induce the expression of numerous antiviral proteins to counteract invading viruses in infected cells and facilitate adaptive immune response against viral infection $(8,32)$. The major IFN-induced antiviral proteins include ISG15, OAS1, and MX1, which amplify antiviral signaling, degrade viral RNA, and inhibit viral gene transcription, respectively (33). The present study showed that recombinant IFN- $\beta$ significantly induces antiviral protein expression and inhibits $\mathrm{MuV}$ replication in LC, macrophages, and SC. The anti-IFN- $\beta$ antibodies significantly increased $\mathrm{MuV}$ replication in testicular somatic cells, which in turn restricted $\mathrm{MuV}$ replication via IFN- $\beta$ production; these findings are in agreement with the results of a previous study, i.e., that type 1 IFN treatment prevents infertility in mumps orchitis patients (34). A high rate of $\mathrm{MuV}$ replication was observed in SC compared to LC. This observation may be explained by the fact that SC produce relatively 
A

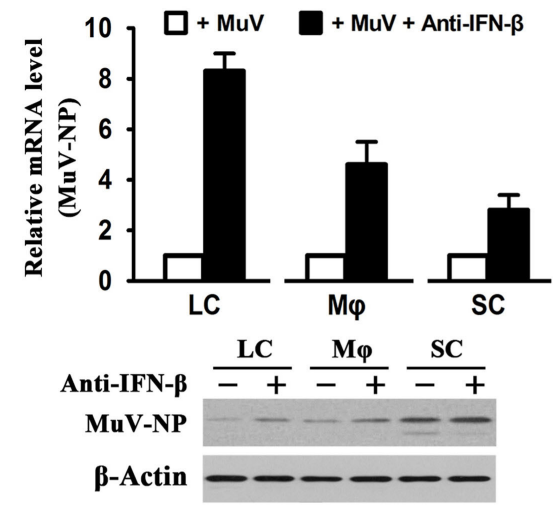

C

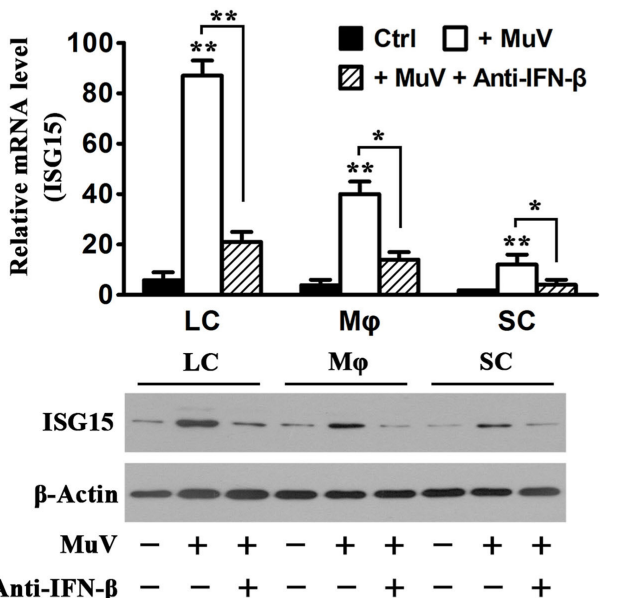

E
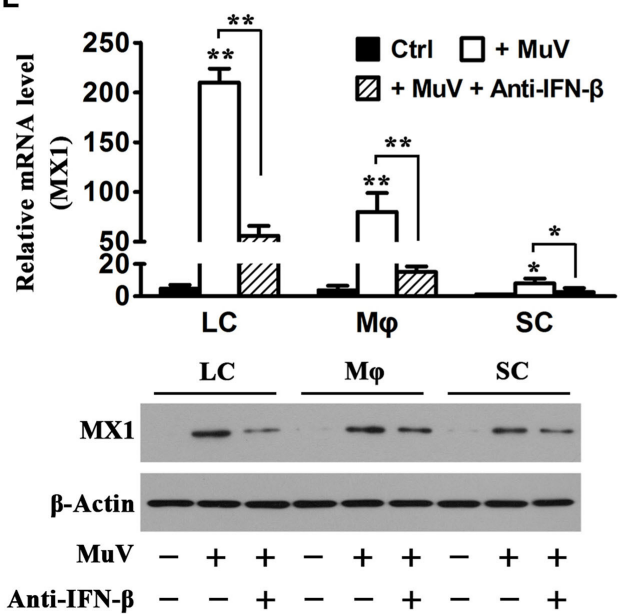

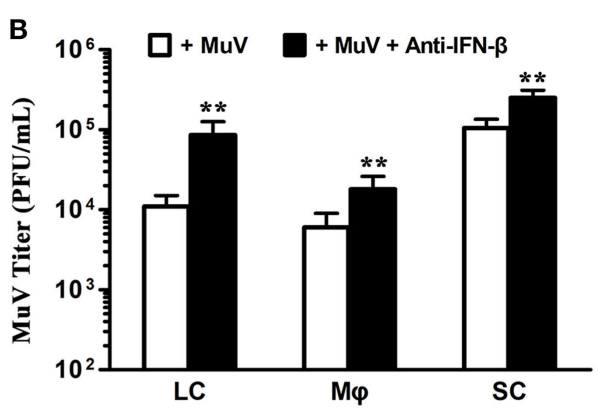

D

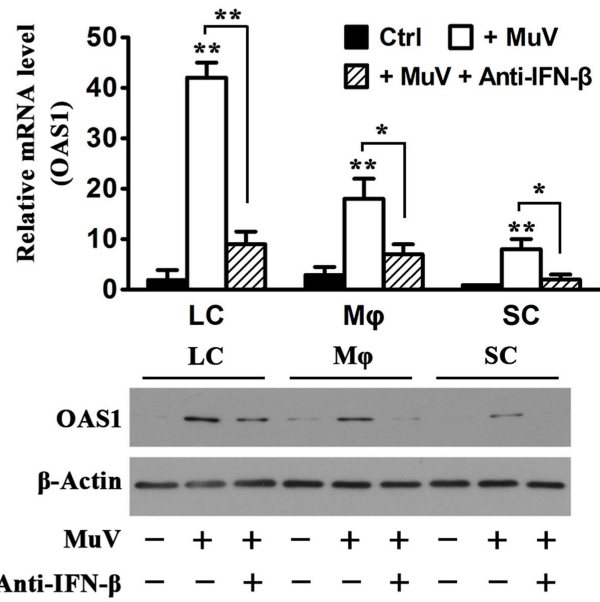

FIGURE 5 | Role of interferon $\boldsymbol{\beta}$ (IFN- $\boldsymbol{\beta}$ ) in mumps virus (MuV)-induced antiviral response. (A) Effect of anti-IFN- $\beta$ antibodies. LC, M $\varphi$, and SC were infected with one multiplicity of infection (MOI) MuV or infected with $1 \mathrm{MOI}$ MuV in the presence of $5 \mu \mathrm{g} / \mathrm{mL}$ anti-IFN- $\beta$ antibodies for $48 \mathrm{~h}$. MuV-NP RNA (upper panel) and protein (lower panel) levels were determined by real-time qRT-PCR and Western blot analysis, respectively. (B) MuV titers. Testicular cells were treated as described in (A). MuV titers in cultured media were determined using plaque forming assay. (C-E) Expression of antiviral proteins. Testicular cells were treated as described in (A). The cells without treatment served as controls (Ctrl). The mRNA (upper panel) and protein (lower panel) levels of IFN-stimulated gene 15 (ISG15) (C), OAS1 (D), and Mx GTPase 1 (MX1) (E) were determined by real-time GRT-PCR and Western blot analysis. Images of Western blot represent at least three independent experiments. Data are presented as the means \pm SEM of three experiments. 
A

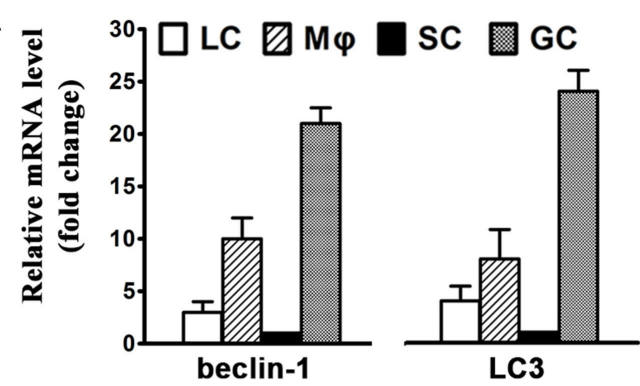

C
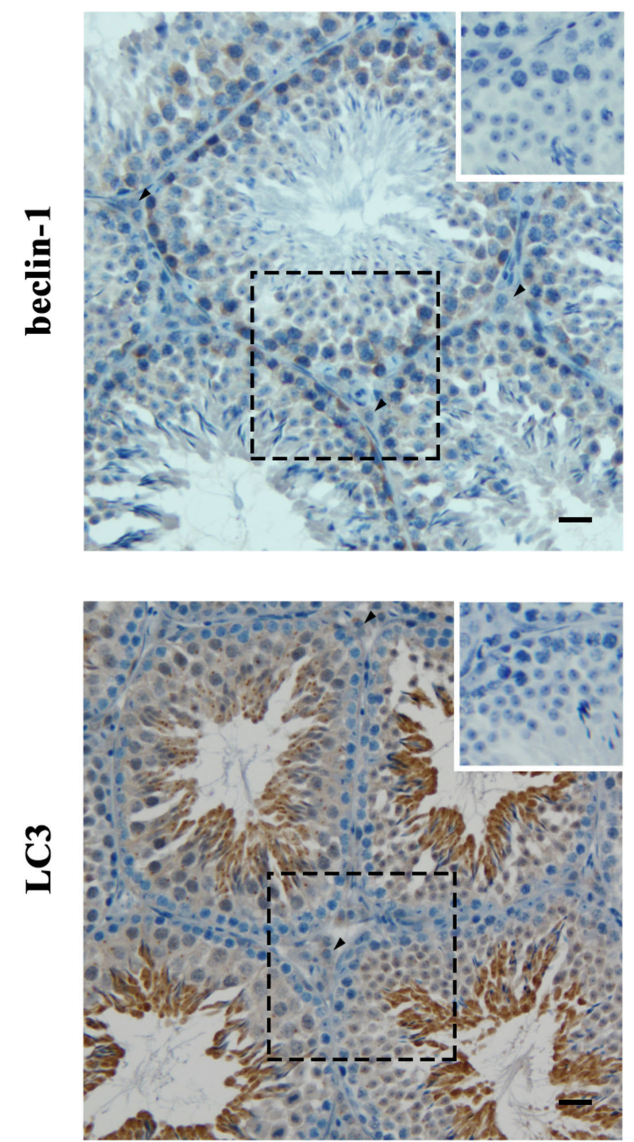

B
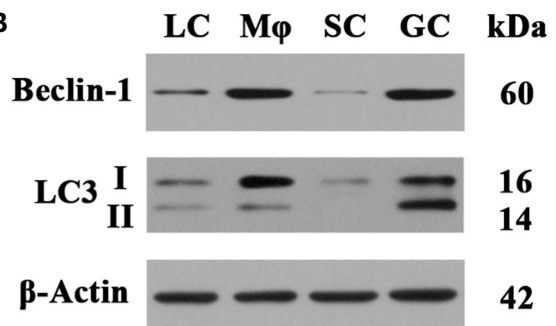

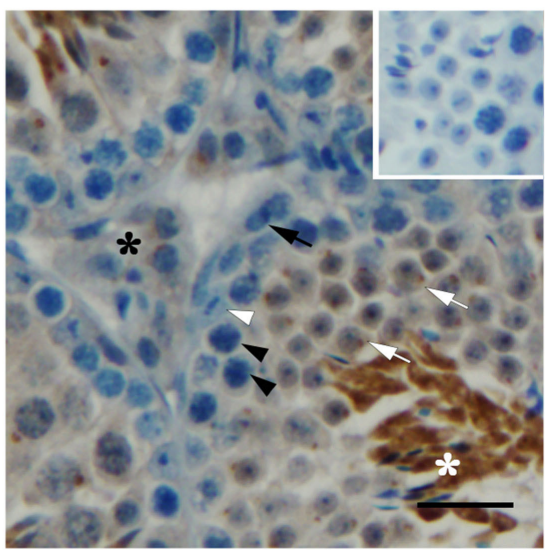

FIGURE 6 | Autophagy-related gene expression. (A) The mRNA levels of beclin-1 and light chain 3 (LC3). Testicular cells were isolated from 4-week-old mice. Relative mRNA levels of beclin-1 and LC3 were determined using real-time qRT-PCR. (B) Protein levels of beclin-1 and LC3. Testicular cell lysates were subjected to Western blot analysis. $\beta$-Actin was used as loading control. (C) Cellular distribution of beclin-1 and LC3. The paraffin sections of the testes from 5-week-old mice were subjected to immunohistochemistry analysis to locate beclin-1 (upper panels) and LC3 (low panels) using specific antibodies. Insets in the upper right corners represent negative controls, in which pre-immune rabbit sera served as primary antibodies. Black arrows, spermatogonia; black arrowheads, spermatocytes; white arrows, round spermatids; white arrowheads, Sertoli cells (SC); black asterisks, interstitial cells; white asterisks, elongating spermatids. Data are presented as the means \pm SEM of three experiments. Images represent at least three independent experiments. Scale bars, $20 \mu \mathrm{m}$.

low levels of type 1 IFNs in response to $\mathrm{MuV}$ infection compared to LC (12). The present study showed that SC expressed lower levels of antiviral proteins than $\mathrm{LC}$ after $\mathrm{MuV}$ infection. However, the in vitro data may not reflect the in vivo situation because IFNs produced by LC should enhance the antiviral response in $\mathrm{SC}$ in a paracrine manner. This speculation is supported by the observation that recombinant IFN- $\beta$ significantly inhibited $\mathrm{MuV}$ replication and induced antiviral protein expression in SC. The antiviral response and $\mathrm{MuV}$ replication in testicular cells in vivo remain to be clarified.

Testicular macrophages display immunosuppressive properties in favor of the immunoprivileged environment in the 
A

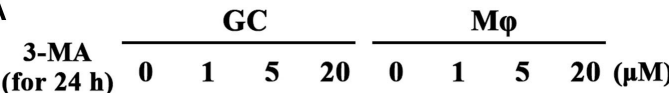
LC3 ${ }_{\text {II }}=2-2=$ B-Actin

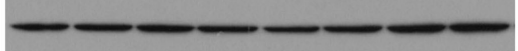

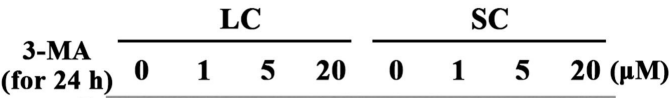
LC3

B-Actin

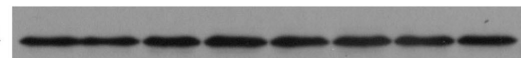

B

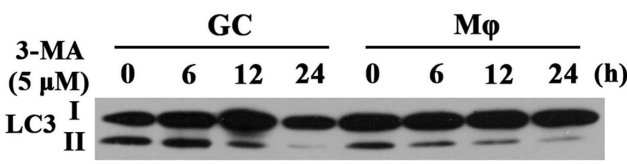

及-Actin
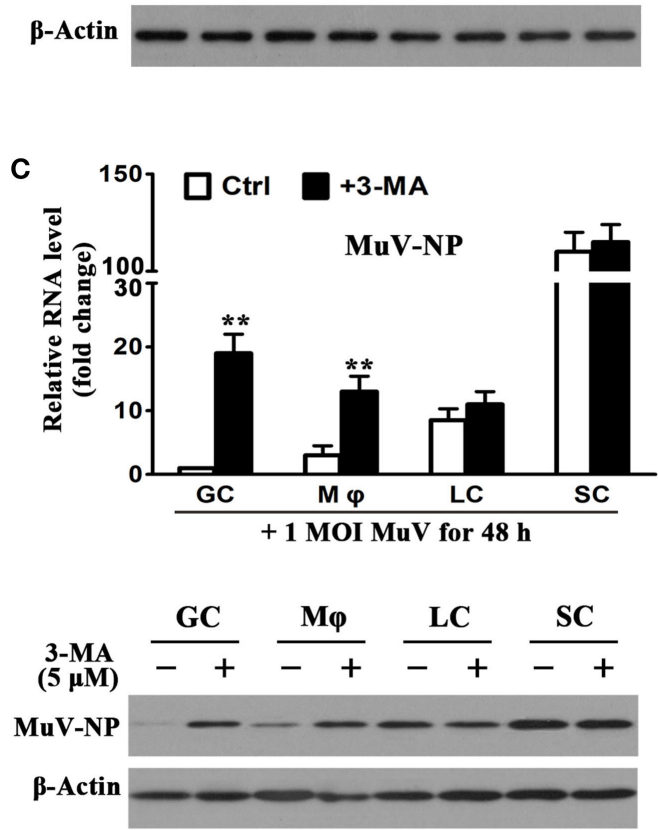

D

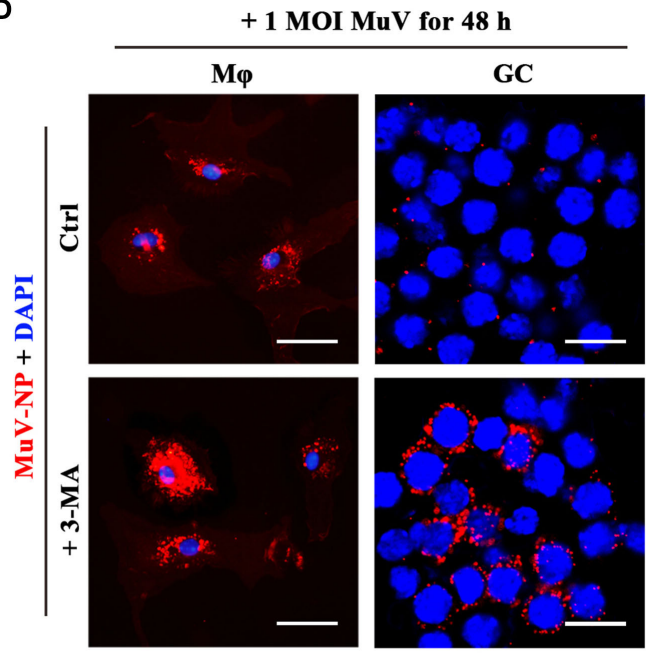

E

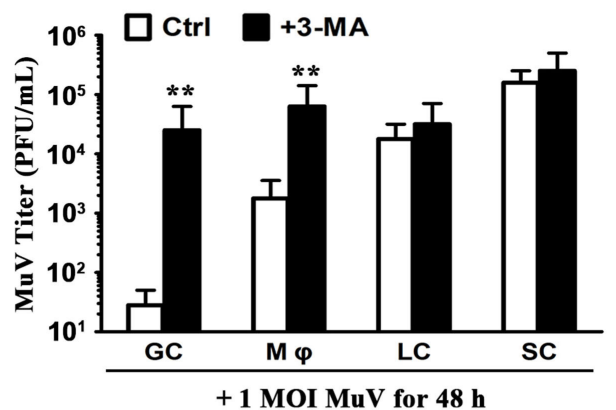

$\mathbf{F}$

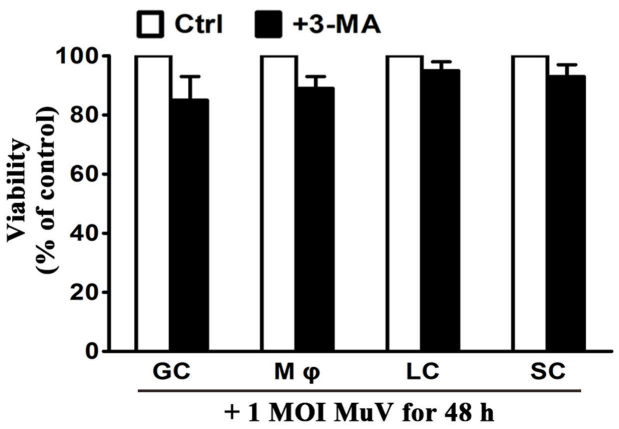

FIGURE 7 | Role of autophagy in limiting mumps virus (MuV) replication. (A) Inhibition of autophagy by 3-methyladenine (3-MA). Germ cells (GC) and

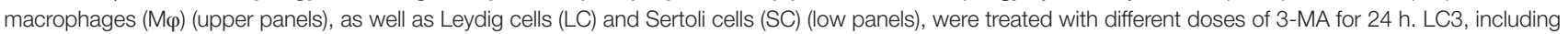
LC3-I and LC3-II, were determined by Western blot analysis. (B) A time-dependent effect of 3-MA on LC3 expression. GC and M $\varphi$ were treated with $5 \mu$ M 3-MA for specific durations. LC3 levels were analyzed by Western blot analysis. (C) Effect of 3-MA on MuV-NP levels. Testicular cells were infected with one multiplicity of infection (MOI) MuV in the absence (Ctrl) and presence of $5 \mu \mathrm{M}$ 3-MA. After $48 \mathrm{~h}$, MuV-NP RNA levels were determined using real-time qRT-PCR (upper panel), and its protein levels were assessed by Western blot analysis. (D) Intracellular MuV particles. M $\varphi$ (left panels), and GC (right panels) were treated as described in (C) for 48 h. MuV particles were detected by immunofluorescence staining using antibodies against MuV-NP. Cell nuclei were visualized using staining with DAPI. Scale bars, 20 um. (E) MuV titers. Cells were treated as described in (C) for $48 \mathrm{~h}$. MuV titers in media were determined using plaque forming assay. The limit of detection was 10. (F) Cell viability. Cells were treated as described in (C) for 48 h. Cell viability was assessed by MTT assay. Images represent at least three independent experiments. Data are presented as the means \pm SEM of three experiments $\left.{ }^{\star \star} p<0.01\right)$.

testis $(35,36)$. Rat testicular macrophages produce fewer IFNs than LC after infection with Sendai viruses (37). However, the present study showed that $\mathrm{MuV}$ replicated at comparable efficiencies in LC and macrophages. This observation implies that testicular macrophages should possess other mechanism to restrict $\mathrm{MuV}$ replication in addition to the IFN pathway. Particularly, IFN- $\beta$ neither induce antiviral protein expression nor inhibited $\mathrm{MuV}$ replication in male GC, thereby suggesting 
that male GC adopted an IFN-independent defense against $\mathrm{MuV}$ replication.

Autophagy plays an important role in recycling intracellular components and removing dysfunctional organelles to adapt to starvation stress and maintain cellular homeostasis (38). Recent reports have described the roles of autophagy in regulating spermatogenesis $(20,39)$. Autophagy is also involved in the cellular defense against microbial infections (40). Autophagosomes may directly uptake and degrade invading viruses intracellularly (41). The present study showed that male GC and macrophages abundantly expressed beclin-1 and LC3, thereby indicating that these cells are well equipped with an autophagic machinery. The 3-MA, which is an inhibitor of autophagy, inhibited LC3-II level. LC3-II is a marker of active autophagy (42). Remarkably, the presence of 3-MA significantly increased $\mathrm{MuV}$ replication in male GC and macrophages. These results suggest that autophagy restricts $\mathrm{MuV}$ replication in these cell types. On the other hand, both IFN response and autophagy limited $\mathrm{MuV}$ replication in testicular macrophages, and autophagy is essential to block $\mathrm{MuV}$ replication in male GC. In contrast, beclin-1 and LC3 were faintly expressed in Leydig and SC. Accordingly, 3-MA did not significantly affect $\mathrm{MuV}$ replication in Leydig and SC. Therefore, autophagy should not be involved in the control of $\mathrm{MuV}$ replication in Leydig and SC. The role of autophagy in restricting MuV replication in the testicular cells needs further corroboration through genetic analysis. In this context, cell-specific knockout of autophagy genes would be an ideal model to confirm the antiviral defense of autophagy in testicular cells.

Recent studies demonstrated that Zika virus infection damages the testis in mice $(43,44)$. Similar to $\mathrm{MuV}$, Zika virus induced inflammatory cytokine production in testicular somatic cells but not in GC (44). Interestingly, Zika virus was detected in testicular somatic cells and spermatogenic stem cells but not detected in the developing GC. The mechanisms underlying the cell-specific infection of Zika virus remain to be clarified, which should refer to the present study on $\mathrm{MuV}$.

Viral infection in male GC may be transmitted to female partners and fetus, thus leading to virus spreading (45). Therefore, the antiviral defense of male GC are particularly important not

\section{REFERENCES}

1. Davis NF, McGuire BB, Mahon JA, Smyth AE, O’Malley KJ, Fitzpatrick JM. The increasing incidence of mumps orchitis: a comprehensive review. BJU Int (2010) 105:1060-5. doi:10.1111/j.1464-410X.2009.09148.x

2. Rubin S, Eckhaus M, Rennick LJ, Bamford CG, Duprex WP. Molecular biology, pathogenesis and pathology of mumps virus. J Pathol (2015) 235:242-52. doi:10.1002/path.4445

3. Litman N, Baum SG. Mumps virus. 7th ed. In: Mandell GL, Bennett JE, Dolin $\mathrm{R}$, editors. Principles and Practice of Infectious Diseases. Philadelphia, PA: Churchill Livingstone Elsevier (2010). p. 2201-6.

4. Manson AL. Mumps orchitis. Urology (1990) 36:355-8. doi:10.1016/00904295(90)80248-L

5. Bjorvatn B. Mumps virus recovered from testicles by fine-needle aspiration biopsy in cases of mumps orchitis. Scand J Infect Dis (1973) 5:3-5. doi:10.3109/inf.1973.5.issue-1.02

6. Jalal H, Bahadur G, Knowles W, Jin L, Brink N. Mumps epididymo-orchitis with prolonged detection of virus in semen and the development of antisperm antibodies. J Med Virol (2004) 73:147-50. doi:10.1002/jmv.10544 only for healthy male fertility but also for limiting the vertical transmission of viruses. Notably, the late stages of male GC are separated from the components of the immune system and antiviral drugs by the blood-testis barrier (BTB). The innate antiviral defense of the male GC behind the BTB should be critical for counteracting viral infection. Moreover, the antiviral response via the autophagy pathway does not require the production of proinflammatory cytokines, whereas the innate immune responses to microbial pathogens produce numerous pro-inflammatory cytokines. High levels of certain pro-inflammatory cytokines can be harmful to spermatogenesis (46-50). Therefore, autophagy should be a particularly suitable means for the antiviral defense of male GC.

In summary, the present study examined the testicular cell type-specific defense against $\mathrm{MuV}$ replication in vitro. IFN- $\beta$ restricts $\mathrm{MuV}$ replication in Leydig and SC. Autophagy may play a role in blocking $\mathrm{MuV}$ replication in male GC. Testicular macrophages utilize both autophagy and IFN pathways to control $\mathrm{MuV}$ replication. These results provide novel insights into the mechanisms underlying the innate defense against $\mathrm{MuV}$ replication in testicular cells and suggest that manipulations of cell type-appropriate antiviral response should be considered as preventive and therapeutic approaches against $\mathrm{MuV}$ infection in the testis.

\section{AUTHOR CONTRIBUTIONS}

$\mathrm{HW}, \mathrm{XZ}$, and $\mathrm{DH}$ designed the project and experiments. HW, XZ, FW, QJ, and LS carried out most of the experiments. HW, MG, and WL isolated the primary cell, and QL isolated and identified $\mathrm{MuV}$. BG, CS, and YC carried out statistical analysis. DH and HW wrote the paper.

\section{FUNDING}

This work was supported by the National Natural Science Foundation of China (Grant Nos. 31261160491, 31371518, 31272406) and the Major State Basic Research Project of China (Nos. 2015CB943001, 2016YFA0101001).

7. Xu P, Huang Z, Gao X, Michel FJ, Hirsch G, Hogan RJ, et al. Infection of mice, ferrets, and rhesus macaques with a clinical mumps virus isolate. $J$ Virol (2013) 87:8158-68. doi:10.1128/JVI.01028-13

8. Sadler AJ, Williams BR. Interferon-inducible antiviral effectors. Nat Rev Immunol (2008) 8:559-68. doi:10.1038/nri2314

9. Wu J, Chen ZJ. Innate immune sensing and signaling of cytosolic nucleic acids. Annu Rev Immunol (2014) 32:461-88. doi:10.1146/ annurev-immunol-032713-120156

10. Diamond MS, Farzan M. The broad-spectrum antiviral functions of IFIT and IFITM proteins. Nat Rev Immunol (2013) 13:46-57. doi:10.1038/nri3344

11. Crouse J, Kalinke U, Oxenius A. Regulation of antiviral T cell responses by type I interferons. Nat Rev Immunol (2015) 15:231-42. doi:10.1038/nri3806

12. Wu H, Shi L, Wang Q, Cheng L, Zhao X, Chen Q, et al. Mumps virus-induced innate immune responses in mouse Sertoli and Leydig cells. Sci Rep (2016) 6:19507. doi:10.1038/srep19507

13. Choi AM, Ryter SW, Levine B. Autophagy in human health and disease. $N$ Engl J Med (2013) 368:651-62. doi:10.1056/NEJMra1205406

14. Wileman T. Autophagy as a defence against intracellular pathogens. Essays Biochem (2013) 55:153-63. doi:10.1042/bse0550153 
15. Deretic V, Saitoh T, Akira S. Autophagy in infection, inflammation and immunity. Nat Rev Immunol (2013) 13:722-37. doi:10.1038/nri3532

16. Matsunaga K, Saitoh T, Tabata K, Omori H, Satoh T, Kurotori N, et al. Two Beclin 1-binding proteins, Atg14L and Rubicon, reciprocally regulate autophagy at different stages. Nat Cell Biol (2009) 11:385-96. doi:10.1038/ ncb 1846

17. Weidberg H, Shvets E, Shpilka T, Shimron F, Shinder V, Elazar Z. LC3 and GATE-16/GABARAP subfamilies are both essential yet act differently in autophagosome biogenesis. EMBO J (2010) 29:1792-802. doi:10.1038/ emboj. 2010.74

18. Li N, Wang T, Han D. Structural, cellular and molecular aspects of immune privilege in the testis. Front Immunol (2012) 3:152. doi:10.3389/ fimmu.2012.00152

19. Zhao S, Zhu W, Xue S, Han D. Testicular defense systems: immune privilege and innate immunity. Cell Mol Immunol (2014) 11:428-37. doi:10.1038/ cmi.2014.38

20. Shang $\mathrm{Y}$, Wang H, Jia $\mathrm{P}$, Zhao H, Liu C, Liu W, et al. Autophagy regulates spermatid differentiation via degradation of PDLIM1. Autophagy (2016) 12:1575-92. doi:10.1080/15548627.2016.1192750

21. Zhu W, Chen Q, Yan K, Liu Z, Li N, Zhang X, et al. RIG-I-like receptors mediate innate antiviral response in mouse testis. Mol Endocrinol (2013) 27:1455-67. doi:10.1210/me.2013-1075

22. Klinefelter GR, Hall PF, Ewing LL. Effect of luteinizing hormone deprivation in situ on steroidogenesis of rat Leydig cells purified by a multistep procedure. Biol Reprod (1987) 36:769-83. doi:10.1095/biolreprod36.3.769

23. Hume DA, Perry VH, Gordon S. The mononuclear phagocyte system of the mouse defined by immunohistochemical localisation of antigen F4/80: macrophages associated with epithelia. Anat Rec (1984) 210:503-12. doi:10.1002/ ar.1092100311

24. Wang T, Zhang X, Chen Q, Deng T, Zhang Y, Li N, et al. Toll-like receptor 3-initiated antiviral responses in mouse male germ cells in vitro. Biol Reprod (2012) 86:106. doi:10.1095/biolreprod.111.096719

25. Sharpe RM, McKinnell C, Kivlin C, Fisher JS. Proliferation and functional maturation of Sertoli cells, and their relevance to disorders of testis function in adulthood. Reproduction (2003) 125:769-84. doi:10.1530/rep.0.1250769

26. Liang Y, Ma J, Li C, Chen Y, Liu L, Liao Y, et al. Safety and immunogenicity of a live attenuated mumps vaccine: a phase I clinical trial. Hum Vaccin Immunother (2014) 10:1382-90. doi:10.4161/hv.28334

27. Livak KJ, Schmittgen TD. Analysis of relative gene expression data using real-time quantitative PCR and the 2(-Delta Delta C(T)) Method. Methods (2001) 25:402-8. doi:10.1006/meth.2001.1262

28. Randall RE, Goodbourn S. Interferons and viruses: an interplay between induction, signalling, antiviral responses and virus countermeasures. J Gen Virol (2008) 89:1-47. doi:10.1099/vir.0.83391-0

29. Centers for Disease Control and Prevention. Update: mumps outbreak - New York and New Jersey, June 2009 - January 2010. MMWR Morb Mortal Wkly Rep (2010) 59:125-9.

30. Schuppe HC, Meinhardt A, Allam JP, Bergmann M, Weidner W, Haidl G. Chronic orchitis: a neglected cause of male infertility? Andrologia (2008) 40:84-91. doi:10.1111/j.1439-0272.2008.00837.x

31. Philip J, Selvan D, Desmond AD. Mumps orchitis in the non-immune postpubertal male: a resurgent threat to male fertility? BJU Int (2006) 97:138-41. doi:10.1111/j.1464-410X.2006.05902.x

32. Iwasaki A, Medzhitov R. Regulation of adaptive immunity by the innate immune system. Science (2010) 327:291-5. doi:10.1126/science.1183021

33. Schoggins JW, Rice CM. Interferon-stimulated genes and their antiviral effector functions. Curr Opin Virol (2011) 1:519-25. doi:10.1016/j. coviro.2011.10.008

34. Ku JH, Kim YH, Jeon YS, Lee NK. The preventive effect of systemic treatment with interferon-alpha2B for infertility from mumps orchitis. BJU Int (1999) 84:839-42. doi:10.1046/j.1464-410x.1999.00273.x

35. Winnall WR, Muir JA, Hedger MP. Rat resident testicular macrophages have an alternatively activated phenotype and constitutively produce interleukin-10 in vitro. J Leukoc Biol (2011) 90:133-43. doi:10.1189/jlb. 1010557

36. Bhushan S, Tchatalbachev S, Lu Y, Frohlich S, Fijak M, Vijayan V, et al. Differential activation of inflammatory pathways in testicular macrophages provides a rationale for their subdued inflammatory capacity. J Immunol (2015) 194:5455-64. doi:10.4049/jimmunol.1401132

37. Dejucq N, Lienard MO, Guillaume E, Dorval I, Jegou B. Expression of interferons-alpha and -gamma in testicular interstitial tissue and spermatogonia of the rat. Endocrinology (1998) 139:3081-7. doi:10.1210/en.139. 7.3081

38. Yang Z, Klionsky DJ. Eaten alive: a history of macroautophagy. Nat Cell Biol (2010) 12:814-22. doi:10.1038/ncb0910-814

39. Liu C, Wang H, Shang Y, Liu W, Song Z, Zhao H, et al. Autophagy is required for ectoplasmic specialization assembly in sertoli cells. Autophagy (2016) 12:814-32. doi:10.1080/15548627.2016.1159377

40. Deretic V. Autophagy as an innate immunity paradigm: expanding the scope and repertoire of pattern recognition receptors. Curr Opin Immunol (2012) 24:21-31. doi:10.1016/j.coi.2011.10.006

41. Richetta C, Faure M. Autophagy in antiviral innate immunity. Cell Microbiol (2013) 15:368-76. doi:10.1111/cmi.12043

42. McLeland CB, Rodriguez J, Stern ST. Autophagy monitoring assay: qualitative analysis of MAP LC3-I to II conversion by immunoblot. Methods Mol Biol (2011) 697:199-206. doi:10.1007/978-1-60327-198-1_21

43. Govero J, Esakky P, Scheaffer SM, Fernandez E, Drury A, Platt DJ, et al. Zika virus infection damages the testes in mice. Nature (2016) 540:438-42. doi:10.1038/nature20556

44. Ma W, Li S, Ma S, Jia L, Zhang F, Zhang Y, et al. Zika virus causes testis damage and leads to male infertility in mice. Cell (2016) 167:1511-1524. e1510. doi:10.1016/j.cell.2016.11.016

45. Apari P, de Sousa JD, Muller V. Why sexually transmitted infections tend to cause infertility: an evolutionary hypothesis. PLoS Pathog (2014) 10:e1004111. doi:10.1371/journal.ppat.1004111

46. Theas MS, Rival C, Jarazo-Dietrich S, Jacobo P, Guazzone VA, Lustig L. Tumour necrosis factor-alpha released by testicular macrophages induces apoptosis of germ cells in autoimmune orchitis. Hum Reprod (2008) 23:1865-72. doi:10.1093/humrep/den240

47. Rival C, Theas MS, Guazzone VA, Lustig L. Interleukin-6 and IL-6 receptor cell expression in testis of rats with autoimmune orchitis. J Reprod Immunol (2006) 70:43-58. doi:10.1016/j.jri.2005.10.006

48. Hong CY, Park JH, Ahn RS, Im SY, Choi HS, Soh J, et al. Molecular mechanism of suppression of testicular steroidogenesis by proinflammatory cytokine tumor necrosis factor alpha. Mol Cell Biol (2004) 24:2593-604. doi:10.1128/ MCB.24.7.2593-2604.2004

49. Siu MK, Lee WM, Cheng CY. The interplay of collagen IV, tumor necrosis factor-alpha, gelatinase B (matrix metalloprotease-9), and tissue inhibitor of metalloproteases-1 in the basal lamina regulates Sertoli cell-tight junction dynamics in the rat testis. Endocrinology (2003) 144:371-87. doi:10.1210/ en.2002-220786

50. Hales DB. Interleukin-1 inhibits Leydig cell steroidogenesis primarily by decreasing 17 alpha-hydroxylase/C17-20 lyase cytochrome P450 expression. Endocrinology (1992) 131:2165-72. doi:10.1210/endo.131.5.1425417

Conflict of Interest Statement: The authors declare that the research was conducted in the absence of any commercial or financial relationships that could be construed as a potential conflict of interest.

Copyright (๔ 2017 Wu, Zhao, Wang, Jiang, Shi, Gong, Liu, Gao, Song, Li, Chen and Han. This is an open-access article distributed under the terms of the Creative Commons Attribution License (CC BY). The use, distribution or reproduction in other forums is permitted, provided the original author(s) or licensor are credited and that the original publication in this journal is cited, in accordance with accepted academic practice. No use, distribution or reproduction is permitted which does not comply with these terms. 